NEW BOOKS.

Die Lichtelektrischen Erscheinungen. By R. PohL AND P. Pringsheim. Braunschweig: Vieweg and Sohn, I9I4. Pp. I + II4. Price Mk 3.

This monograph, on photoelectric phenomena, deals especially with the subject as it has been developed through the researches of the authors, and is therefore more limited in its scope than the recently published monographs by Ries, and Stanley Allen.

Special prominence is given to those phases of the subject dealing with the selective and normal photo-effects of metals.

The work includes chapters on the photo-effect of non-metallically conducting bodies, the effect of surface layers on the photo-effect, and the ionization of gases by light. The closing chapter gives a resumé of the work done by Lindemann, Debyje Sommerfeld and others on the interpretation of photoelectric action in the light of the quantum theory.

The bibliography which is appended is most exhaustive and is brought down to September, I9I3. It is regrettable that the work was written before the publication of papers by Wiedemann and Hallwachs, Friedenhagen, Küstner and Hughes on the part played by occluded gases in photoelectric phenomena.

J. C. M.

La Telegraphie et La Telephonie Simultanees et La Telephonie Multiple. By

K. Berger. Paris: Gauthier-Villars, I9I3. Pp. I + I34.

The book contains three chapters: (I) Telephony over telegraph lines; (2) Telegraphy over telephone lines; and (3) The simultaneous transmission of several telephonic messages over the same line. The treatment is rather technical in character, but the physicist will find much of interest, especially the historical data and the clear presentation of the underlying scientific principles with which each chapter is introduced. The book is a French translation by Le Normand of the German work.

K. E. G.

Taschenbuch für Mathematiker und Physiker. By Felix Auerbach AND

Rudolf Rothe. Leipzig: Druck, 1913. Pp. $x+463$. Price, Mk. 6.

Into this small book is compressed a large amount of valuable information, both in mathematics and physics. Beginning with an account of the life of Friedrich Kohlrausch, there follow a number of numerical tables of various functions, and a very compendious presentation of various departments of mathematics including a short account of integral equations. In physics there 
are also useful tables, with much general information. Particularly interesting is an account of the quantum theory by Sommerfeld. A list of recent books is included.

A. G. W.

Collected Papers in Physics and Engineering. By James Thomson. Cambridge: University Press, I912. Pp. civ +484 .

This volume adds to the debt of gratitude which students of physics owe to Sir Joseph Larmor for the editorial labor and skill he has devoted to the collection, in convenient and accessible form, of the scientific papers and correspondence of the great physicists of the Victorian era. In the present instance he has had the assistance of James Thomson, M.A., the son of Professor Thomson; and the very interesting Biographical Memoir, with which the volume opens, "has been constructed largely out of narratives and recollections obtained by his daughter Mary Hancock Thomson."

James Thomson was two years older than his brother William, and the two were from childhood devotedly attached to each other. It is inevitable that this close association with his more brilliant junior must have had a considerable effect upon his own scientific work; yet these papers show very clearly that James possessed a mind of great independence and originality, and the correspondence between the brothers (a few examples of which are contained in this volume) make it plain that the influence and help were not all on one side. The difference in the characters of the two men are distinctly shown in their published work. After a perusal of the present volume, one is entirely convinced of the accuracy of the statement in the biographical sketch that, as boys and throughout their lives, "James was the more careful and exact, and William the more quick and ready."

James Thomson was, by profession, an engineer and was for many years professor of engineering, first in Queen's College, Belfast, and afterward in the University of Glasgow. He made many investigations and inventions in the subject of hydraulics, accounts of which are contained in the first section of the present volume. He invented a turbine water-wheel, a centrifugal pump and a jet pump which were much used in their time; and he made great improvements in the measurement of running water by weir-boards, especially by his introduction of the triangular notch. One short paper in this section contains his explanation of the "tears of strong wine" which is familiar to all readers of Maxwell's Theory of Heat.

The second division of papers on "Congelation and Liquefaction" begins with the celebrated calculation, from Carnot's theory, of the lowering of the freezing point of water by pressure. As was still customary at the time (1849), notwithstanding the previous work of Mayer, Joule and Helmholtz, the argument assumes, like that of Carnot himself, the perfect conservation of heat. As is well known, the calculation was numerically verified soon after by Lord Kelvin; it is quite plain from his language that the fact that "an entirely novel physical phenomenon was predicted in anticipation of any 
direct experiment" had a great effect upon his mind, and must have contributed to his reluctance to accept Joule's theory until he had, with much difficulty, reconciled it with Carnot's.

The remaining papers of this section (together with some correspondence with Faraday which is included) is mainly concerned with regelation and the plasticity of ice in glaciers; there was much difference of opinion on these subjects, but Thomson's views were well considered and sound, and he maintained them with courage and tenacity even against the great authority of Faraday.

During his residence in Belfast, Thomson was a colleague of Andrews and was deeply interested in his experiments upon the critical state and the continuity of the liquid and gaseous states. His contributions to this subject form the third section of papers. As is well known, he first suggested some of the ideas which were afterward worked out more completely by van der Waals. He also investigated the triple-point and made the first thermodynamic model in three dimensions.

The fourth section on "Dynamics and Elasticity" is perhaps of less general interest than the preceding ones. The paper on "Inertia, Chronometry, Absolute Motion" however might well arrest attention as a fore-runner of the modern doctrine of relativity-especially the statement on p. 380 of the difficulty of defining simultaneity.

The book concludes with three papers on geological subjects, some miscellaneous papers, and an appendix containing three papers of general, rather than scientific, interest.

H. A. B.

Molecular Physics. By James Arnold Crowther, M.A. Philadelphia: P. Blakiston's Son \& Co., I914. Pp. viii + I67. Price, \$1.25.

This little book has been prepared to meet the need of those who desire to know what has been learned through recent researches of the constitution and properties of atoms and molecules.

It contains chapters which deal with the physics of the electron, the properties of alpha rays, positive ray analysis, as developed by Sir J. J. Thomson, the chemistry of the atom in the light of the electron theory, the Zeeman effect, spectral series, the origin of spectra, the kinetic theory of heat, the electronic theory of thermal and electrical conduction, radioactivity and radioactive transformations. It also contains three appendices of mathematical notes illustrating the matter of the text and closes with a table of atomic data, and a bibliography. The book has been written with care and will prove extremely useful.

J. C. M.

La Technique de La Radiotelegraphie. By Dr. Ing. H. ReIn. Paris: GauthierVillars, 1913. Pp. $\mathrm{x}+257$.

This book is a translation into French of the second edition of Rein's Radio- 
telegraphisches Praktikum. It was originally written as a laboratory guide for students of wireless telegraphy, but in its present form it contains much which would not be found in a mere laboratory manual. After a short introduction, discussing the characteristic features of various systems of wireless telegraphy the main part of the book is devoted to a description of high frequency instruments and the best methods for their calibration. Measurements of capacities, self and mutual inductances, wave-length and damping under such conditions as are found in actual practice are given in detail and in each case a large number of different methods is given. Then follows a chapter on generators and receivers of various types. The book closes with a discussion of the guiding principles for the erection of wireless stations.

The illustrations are practically restricted to apparatus used in Germany and the bibliography contains only a few references to publications in any other but the German language. The treatment of the subject is excellent and the book should be found in every laboratory of wireless telegraphy. We are indebted to the translator, G. Viard, to have made this book available to students who are unable to read it in the original.

K. E. G.

Practical Physics. By N. H. Black and H. N. Davis. New York: The Macmillan Company, I913. Pp. ix +487 . Price, \$1.25 net.

This is an elementary physics text-book which follows for the most part established lines. It is a somewhat longer treatise than other elementary textbooks due largely to more descriptions of commercial devices.

E. S. B.

Second Course in Algebra. By William Benjamin Fite, New York:

D. C. Heath and Company, igr4. Pp. v +247.

This is an attractive and clearly written text for students who have had a year of algebra.

F. B.

Elektrische Spektralanalyse chemischer Atome. By Dr. J. Stark. Leipzig:

S. Hirzel, I9I4. Pp. viii + I38. Price, Mk. 5.

This monograph contains an account of the phenomenon of electric resolution of spectral lines recently discovered by Stark, and includes a detailed description of the different experimental methods of observing the effect.

The chapter dealing with the dependence on field intensity of the strength and the distance apart of the electrically resolved constituents of a line as well as that on the analysis of lines of the same series and of different elements is specially well prepared.

The monograph contains a chapter on phenomena allied to the Stark effect, and also one which deals entirely with theoretical considerations regarding it. The bibliography appended is excellent.

J. C. M. 
Experimental Studies in Electricity and Magnetism. By Francis E. Nipher. Philadelphia: P. Blakiston's Son \& Co., I914. Pp. I + 73. Price, \$1.25.

This book contains in connected form the results of Professor Nipher's researches, which have been published from time to time since I9Io by the Academy of Sciences of St. Louis. The author undertakes to obtain evidence from the ordinary electric discharge in air which can be used to decide between the claims of the "one-fluid" and the "two-fluid" theories of electricity. His observations are extremely curious and interesting. They well deserve the consideration of anyone who is concerned with the phenomena of the electric discharge. The author concludes that they can be explained on the "one-fluid" theory. He agrees with Aepinus that this theory necessitates the mutual repulsion of material particles, and believes that he observes this in the explosion of a lead wire into which a discharge passes from a neighboring positive terminal. The creeping of a wire in the direction opposite to that of the corpuscular (i.e., negative) discharge passing along it is remarkable.

A short section at the end of the book deals with the author's observations of the connection between magnetic storms and certain conditions of weather.

W. F. M.

Gas Analysis. By L. M. Dennis. New York: The Macmillan Company, 1913. Pp. xvi + 434. Price, \$2.10.

This book is written for technical chemists and contains descriptions of apparatus and methods for rapid gas analysis. Elementary physical laws are briefly mentioned at the proper places. Some contact with the physicist is made in such chapters as: "The determination of the specific gravity of a gas; the purification of mercury; the determination of the heating value of fuel; the examination of atmospheric air." K. E. G.

Geometry of Four Dimensions. By Henry Parker Manning, New York:

The Macmillan Company, I9I4. Pp. ix + 348. Price, \$2.00.

Aristotle made the statement that "beyond these (three dimensions) there is no other magnitude because these three are all." After an interesting historical introduction, reviewing the development of the geometry of more than three dimensions from its negation by Aristotle until its recognition as a branch of modern mathematics, the author discusses the subject in chapters as follows: The Foundations of Four-Dimensional Geometry; Perpendicularity and Simple Angles; Angles of Two Planes and Angles of Higher Order; Symmetry, Order, and Motion; Hyperpyramids, Hypercones, and the Hypersphere; Euclidean Geometry; Figures with Parallel Elements; Measurement of Volume and Hypervolume in Hyperspace; The Regular Polyhedroids.

F. B.

Mathematical Theory of Heat Conduction. By L. R. INGERsoll AND O. J. Zobel. Boston: Ginn and Company, I9r3. Pp. vi + I7r. Price, \$1.6o.

The authors have succeeded in producing a very attractive short treatise 
on this very important subject to the physicist. By a judicious selection of problems they have managed to include the most important methods and at the same time to treat a great variety of practical questions of interest to the engineer or the geologist. The figures are clear and luminous, and the graphical representation of the approximations by Fourier's series is to be commended. An idea of the physical good sense displayed in the choice of subject-matter may be obtained from the following, chosen at random; the theory of "cold waves," flow in engine-cylinder walls, the fireproof wall, annealing of castings, the formation of ice, all worked out with numerical values.

The mathematician will regret that in the treatment of Fourier's theorem, page 6o, Fourier's error in giving the wrong order of integration is perpetuated, but this will not worry the physicist much, and to him the book is unhesitatingly to be commended.

A. G. W.

College Physiography. By Ralph Stockman Tarr. Published under the Editorial Direction of Lawrence Martin. New York: The Macmillan Company, I9I4. Pp. xxii +837 . Price, \$3.50. (Received.)

The Electrical Conductivity and Ionization Constants of Organic Compounds.

By Heyward Scudder. New York: D. Van Nostrand Company, I9I4. Pp. I +568 . Price $\$ 3.00$.

Besides an explanatory introduction, lists of abbreviations, etc., this book contains three tables. The first consisting of 280 pages, is an alphabetical list of all the organic compounds whose electro-chemical properties have been hitherto studied; under each compound are given values of its specific conductivity and ionization constant as determined by different observers at various temperatures and under a variety of other conditions. In each case crossreferences (by number) are given to the third table, or "Author List," which the author believes to be an almost or quite complete bibliography of the subject from 1889 to I9Io. The second table is an index of the chemical formulæ of the compounds mentioned, and there is at the end of the book a Subject Index giving references to the bibliography.

The work appears to be done in a very thorough and painstaking manner and must have involved great labor. It will doubtless prove of value to all investigators whose work involves the electro-chemical properties of organic compounds.

H. A. B.

Physics of the Household. By C. J. Lynde. New York: The Macmillan Company, I9I4. Pp. xi + 3I3. Price, \$I.25.

"This is an elementary text-book of physics, written for students of household science." It is so distinctly practical in its aim that the treatment of dynamics is reserved for the last chapter and occupies fourteen pages. There is practically no discussion of the theories of physics. The laws of physics are stated concisely and are illustrated by examples of their application in common instruments used about the house, ranging in intricacy of construc- 
tion from the tack lifter to the vacuum cleaner. The book is one which may well serve the purpose for which it is designed but it would not do for use in a course of instruction in which physics is taught for its scientific content or as a medium for the inculcation of scientific method.

On page 59 Henry's law is ascribed to "The American physicist Henry." The Henry of the law was William Henry of Manchester, England. The American physicist Joseph Henry was a younger man by twenty-three years than the other, and could not very well, without extraordinary precocity, have announced a discovery in 1803 , when he was six years old.

W. F. M.

Mechanics and Heat. By W. B. Anderson. New York: McGraw-Hill Book Company, I9I4. Pp. xi +349 . Price, $\$ 2.00$ net.

Professor Anderson has made the interesting attempt of writing a college text on mechanics and heat in which the mathematics is reduced to an amount not much greater than that found in the more advanced high school texts. On the other hand he has placed more emphasis on practical applications and elementary methods of measurement than is usual in college texts.

The book is evidently intended for the instruction of students in agriculture and doubtless serves its purpose for this type of students. The mathematical structure is, however, too light to serve as a foundation for a severe training in engineering. The treatment is very clear and interesting and the illustrations excellent.

K. E. G.

Allgemeine Ergebnisse und Probleme der Naturwissenschaft. By Dr. BerNhard Bavink. Leipzig: S. Hirzel, I9I4. Pp. xiii + 3I4. Price, Mk. 7.

This volume aims at giving a philosophical treatment in a condensed form of some of the more general results and problems of present day science. In the first section the subjects presented include the atomic theory of matter, the equivalence of different forms of energy, the kinetic theory of heat, the electromagnetic theory of light, the electromagnetic nature of mass, the emission and absorption of light, and the principle of relativity. The second section includes a discussion of the bearing of the law of entropy on the problem of the future of the world, and a detailed account of such matters as the configuration and motion of fixed star systems, world history, recent advances in our knowledge of meteorological phenomena, and problems relating to cosmogony generally. The third section is devoted to the problem of life, and deals with the physical and chemical basis of life, the simple living cell, vitalism, the origin of life, the principle of causality in biology, and problems arising from a study of multicellular organisms. In the concluding section the subjects dealt with are the theories of evolution and mutation, and problems dealing with the origin of man and his position in the Universe.

The book contains much that is of great interest to those wishing to ascertain the philosophical bearing of recent contributions to knowledge in different branches of science.

J. C. M. 
Report on Radiation and the Quantum-Theory. By J. H. JEans. London: The Electrician Printing and Publishing Co., Ltd., I9I4. Pp. iv +90. Price 6s.

In this brief but comprehensive report, Professor Jeans discusses the modern problem of radiation and its proposed solution by the quantum theory. For some time past Jeans has been reluctant to concede that the general principle of equipartition of energy, which can be demonstrated for dynamical systems, does not apply to the ether as well as to matter in systems which are in true equilibrium. But in this report he frankly accepts the necessity of assuming that the relations of the ether to matter are not subject to dynamical principles, and admits that some laws other than the Newtonian laws must determine the phenomena of radiation. He shows that the Newtonian laws lead to the Rayleigh-Jeans formula, which is inconsistent with the observed facts, and that the hypothesis of the energy quantum leads to Planck's formula. $\mathrm{He}$ then gives an exposition of Nicholson's theory of line-spectra, and an account of Bohr's theory of the atom and its relations to the emission of radiation. $\mathrm{He}$ also discusses the photoelectric effect and the recent work of Debye and others on the heat capacities of solids and shows that the quantum theory will explain the facts observed. In a final chapter on the physical basis of the quantum theory he discusses most acutely the course which speculation must take in the endeavor to construct a new mechanics which shall be comprehensive enough to contain the laws of radiation. He points out that Einstein's light-quanta are inconsistent with the undulatory theory of light, but gives no definite positive conception of what the quantum is, or of the way in which its theory can be developed. In fact nowhere, except in Planck's preface to his Theory of Radiation, is there given a more striking statement of the necessity for a new theory of the physical universe and of the immense distance which we seem to be from realizing such a theory.

The report is written with all the author's well known brilliancy and clearness, and will take rank with similar reports by other English masters as a physical classic.

\section{W. F. M.}

Elements of General Science. By O. W. Caldwell and W. L. Eikenberry. New York: Ginn and Co., r914. Pp. xiv +308 . Price, \$1.oo.

This book represents a pedagogical effort to properly direct the science instruction in the first year of high school work. It emphasizes in particular the physics and chemistry of air and water. The topics discussed are grouped under five headings, the air, water and its uses, work and energy, the earth's crust, and life upon the earth. The treatment throughout is logical and connected, and the principles developed are illustrated with numerous examples drawn from nature.

The chapters dealing with weather, the relation of air to food production, the distribution of disease germs, the climatic influence of bodies of water, water supplies and sewage disposal, soil physics, plant physics, the world's 
food supply, nutrition, reproduction and the struggle for existence are particularly well written. A book of this character should be in the hands of every teacher of elementary science.

J. C. M.

Photo-Electricity. By Arthur Llewelyn Hughes. Cambridge Press, I9i4. Pp. i-viii + I-I42.

Within a single year three books have appeared on photo-electricity and all of them by men who have been actively engaged in pushing ahead the bounds of knowledge in this field. Nevertheless each book shows marked individuality and no two of them are at all alike. Allen's is the most compendious (220 pages) and Pohl and Pringsheim's the most special, dealing largely with work done at the Physical Institute in Berlin, while Hughes' book is remarkable for its combination of thoroughness with conciseness, for its scholarly fairness to all observers, and for the skill and insight with which the varied facts of photo-electricity are given a theoretical significance. Indeed it is by forsaking entirely the historical method and aiming immediately at the statement and explanation of photo-electric facts as they now stand that Hughes has succeeded so well in compressing a very complete treatment of a large field into I40 pages. In many respects the book is noteworthy. $\quad$ R. A. M.

Mathematics, from the Points of View of the Mathematician and of the Physicist.

By E. W. Hobson. Cambridge: University Press, I9I4. Pp. I +24 . Price, Is.

In this address, delivered originally before the Mathematical and Physical Society of University College, London, Professor Hobson has pointed out, with great clearness and entire impartiality, the reasons which underly the different attitudes of mathematicians and of physicists toward the study of mathematics. The subject is illuminated by the author's great learning and enlivened by characteristic touches of humor and by accounts of significant misunderstandings between some of the great physicists and mathematicians of the past. A student of either science can scarcely fail to derive both pleasure and profit from a perusal of the lecture. H. A. B.

Die Lichtbrechung in Gasen als physikalisches und chemisches Problem. By

Dr. St. Loria. Braunschweig: Vieweg und Sohn, I914. Pp. vi +92. Price, Mk. 3 .

This monograph which is one of the Vieweg collection contains a concise summary of all the work which has been done on the refractivity and dispersion of gases. It contains chapters on the electromagnetic theory of dispersion, the methods of determining the refractivity of gases, the dependence of refractive power of gases on pressure and temperature, and the refractivity and dispersion of compound gases and of gaseous mixtures. The references inserted as footnotes are most complete, and altogether the work is one of the best prepared of those of the series which have been brought to the attention of the reviewer.

J. C. M. 